\title{
The Effects of Age on Hearing and Middle Ear Function
}

\author{
Yasue Uchida ', Hideki Nomura ${ }^{2}$, Akihide Itoh ${ }^{1}$, Tsutomu Nakashima ', Fujiko Ando ${ }^{2}$, \\ Naoakira Niino ${ }^{2}$, and Hiroshi Shimokata ${ }^{2}$
}

\begin{abstract}
Audiometric test results from 933 community dwelling males and females were presented to obtain the norm for each generation after middle age. Three aspects were adopted in this analysis ; the cross-sectional aging transition of pure tone thresholds, the comparison in the selfperceived hearing difficulty among generations and the evaluation of middle ear function using multifrequency tympanometry. Subjects were divided into four age groups; $40 \mathrm{~s}, 50 \mathrm{~s}, 60 \mathrm{~s}$ and 70s. There were statistically significant differences in pure tone thresholds between almost any two age groups at each frequency in both genders, especially at higher frequencies. The pure tone thresholds were also discussed in regard to gender difference and laterality. A contradiction between self-perceived hearing difficulty and auditory accuracy was observed in the elderly generation. Analysis of tympanometric measurements was performed on static admittance at $226 \mathrm{~Hz}$, tympanometric peak pressure at $226 \mathrm{~Hz}$ and resonance frequency of the middle ear. These variables did not show any systematic aging change. However, it was considered they represented the reference values of each generation. J Epidemiol, $2000 ; 10:$ S26-S32.
\end{abstract}

aging, hearing , multifrequency tympanometry, self-perception

\section{INTRODUCTION}

Pathophysiological aging changes can appear in any part of the auditory system from the external ear through the cerebral cortex. It is known that age-related degeneration changes are caused by several complex mechanisms in many anatomical regions in varying proportions ${ }^{1)}$ and this results in large individual differences. It is essential to know the norms for each age generation using diagnostic measurements of auditory function before discussing the process and risk factors of aging to find a prophylaxis as a goal.

On the other hand, in the aspects of the management and rehabilitative intervention in age-related hearing loss, it is also necessary to know to what extent the individuals assess their own disability. Generally, hearing disabilities in the elderly may reflect two components; peripheral and central processing impairments. The impairment of the central component could worsen communication problems ${ }^{2,3)}$. It is, however, reported that the self-perceived hearing disability in elderly listeners is less than that in younger listeners ${ }^{4,5,6)}$. It is said that elderly listeners may misunderstand the spoken message but respond with confidence that they are correct and fewer demands on communication, or a gradual progression of hearing loss may make them unaware.

The National Institute for Longevity Sciences, Longitudinal Study of Aging (NILS-LSA) was designed to represent the least biased sample in Japan. The present study provided information regarding the normative data of the auditory system, including pure tone thresholds, tympanometric variables and self-perceived hearing difficulty.

\section{MATERIALS AND METHODS}

\section{Subjects}

The subjects were randomly selected from resident registrations of Ohbu-city and Higashiura-town, located in the central area of Japan. In the period from November, 1997 to March, 1999, 1130 people participated in the ongoing NILS-LSA. All

\footnotetext{
'Department of Otorhinolaryngology, Nagoya University School of Medicine.

${ }^{2}$ Department of Epidemiology, National Institute for Longevity Sciences.

Address for correspondence : Dr. Yasue Uchida, Department of Otorhinolaryngology, Nagoya University School of Medicine 65 Tsuruma-cho, Showa-ku, Nagoya, 466-8550 Japan.
} 
participants gave informed consent and will be examined every two years longitudinally. The age at the baseline is to be 40 to 79 years old and the number of subjects in each decade (40s, $50 \mathrm{~s}, 60 \mathrm{~s}, 70 \mathrm{~s})$ is to be the same.

All participants were reviewed by a series of questionnaires, including demographic characteristics, personal history, family history and various medical problems. One hundred ninetyfour subjects who self-reported a history of ear disease in the questionnaire were eliminated in this analysis, leaving 936 participants who were examined to show the reference values of audiometric tests. The gender and age distribution of the subjects is shown in Table 1. Self-reported hearing problems were able to be checked in 1066 participants.

\section{Instrumentation and procedures}

Pure tone audiometric tests were performed with a diagnostic audiometer (AA-73A, RION, Tokyo), calibrated according to JIS (Japanese Industrial Standards T 1201). Air conduction thresholds at octave intervals from 500 to $8000 \mathrm{~Hz}$ and bone conduction thresholds at octave intervals from 500 to $4000 \mathrm{~Hz}$ were obtained. The thresholds over the maximum output level of this audiometer were treated as shown in Table 2.

In the analysis of self-perceived hearing difficulty, the following question among 15 otological questions was focused ; "Do you think you have hearing impairment?", with the alternatives being ; "Yes" "Occasionally" "No". The answers, "Yes" and "Occasionally" were put together in the awareness of hearing difficulty in the present analysis.

Middle ear function was assessed with a middle ear analyzer (Grason Stadler model 33, version 2, Lucas Grason-Stadler,

Table 1. Number of subjects by gender and age group without history of ear diseases.

\begin{tabular}{cccc}
\hline Age Group & Male & Female & Total \\
\hline $40-49$ & $128(145)$ & $117(155)$ & $245(300)$ \\
$50-59$ & $116(135)$ & $117(149)$ & $233(284)$ \\
$60-69$ & $109(139)$ & $117(134)$ & $226(273)$ \\
$70-79$ & $119(135)$ & $113(138)$ & $232(273)$ \\
Total & $472(554)$ & $464(576)$ & $936(1130)$ \\
\hline
\end{tabular}

Numbers in parentheses are the total number of participants.
Inc. Milford, NH) . The first measurement of the test battery was tympanometry performed at a probe tone frequency of $226 \mathrm{~Hz}$. Admittance was calculated and shown by an equivalent volume of air in ml. Static admittance and tympanometric peak pressure were taken as variables.

The second measurement of tympanometry was a series of multiple frequency tests. The probe tone automatically swept in frequencies from $250 \mathrm{~Hz}$ to $2000 \mathrm{~Hz}$ in $50 \mathrm{~Hz}$ steps at the start-pressure (+ $200 \mathrm{daPa})$. Susceptance and phase measurements were stored in memory. The next tympanogram was run at $226 \mathrm{~Hz}$ and peak data were identified. A second probe tone sweep occurred at peak pressure. The change in susceptance values and phase values between the first sweep and the second sweep of frequencies were calculated and plotted on graphic displays as a function of frequency. The resonance frequency of the test ear was identified as a frequency at which the peak to tail difference values for acoustic susceptance was 0 acoustic mmhos.

\section{Statistical analysis}

Data were processed and analyzed using Statistical Analysis System (SAS) version 6.12 software ${ }^{\text {}}$. Gender differences and laterality in pure tone thresholds were tested with a t-test ( $T$ TEST procedure). Age differences in pure tone thresholds were tested using Tukey's multiple comparison method, and trends in pure tone thresholds by age were also examined (GLM procedure). Self-perceived hearing difficulty was compared between two age groups (under 60 years vs. 60 years and over) with a t-test. Spearman's correlation coefficients between age and pure tone thresholds were calculated in octave intervals from $500 \mathrm{~Hz}$ to $8000 \mathrm{~Hz}$ (CORR procedure).

\section{RESULTS}

\section{Pure tone thresholds}

The upper two panels of Figure 1 show the mean air conduction pure tone thresholds in $\mathrm{dBHL}$ (dB Hearing Level) and standard errors of the right ear for males and females by four age groups and the lower two panels show those of the left ear. As mentioned earlier, the subjects who self-reported a history of ear disease in the questionnaire were eliminated.

Table 2. If no response occurred at the maximum output level of the audiometer, the threshold was treated as follows:

\begin{tabular}{rccccc}
\hline & \multicolumn{2}{c}{ Air conduction } & & \multicolumn{2}{c}{ Bone conduction } \\
\cline { 2 - 3 } \cline { 5 - 6 } & Maximum output level & Input level & & Maximum output level & Input level \\
\hline $500 \mathrm{~Hz}$ & 100 & 105 & & 65 & 70 \\
$1000 \mathrm{~Hz}$ & 100 & 105 & & 70 & 75 \\
$2000 \mathrm{~Hz}$ & 100 & 105 & & 70 & 75 \\
$4000 \mathrm{~Hz}$ & 100 & 105 & & 60 & 65 \\
$8000 \mathrm{~Hz}$ & 95 & 100 & & & \\
\hline
\end{tabular}



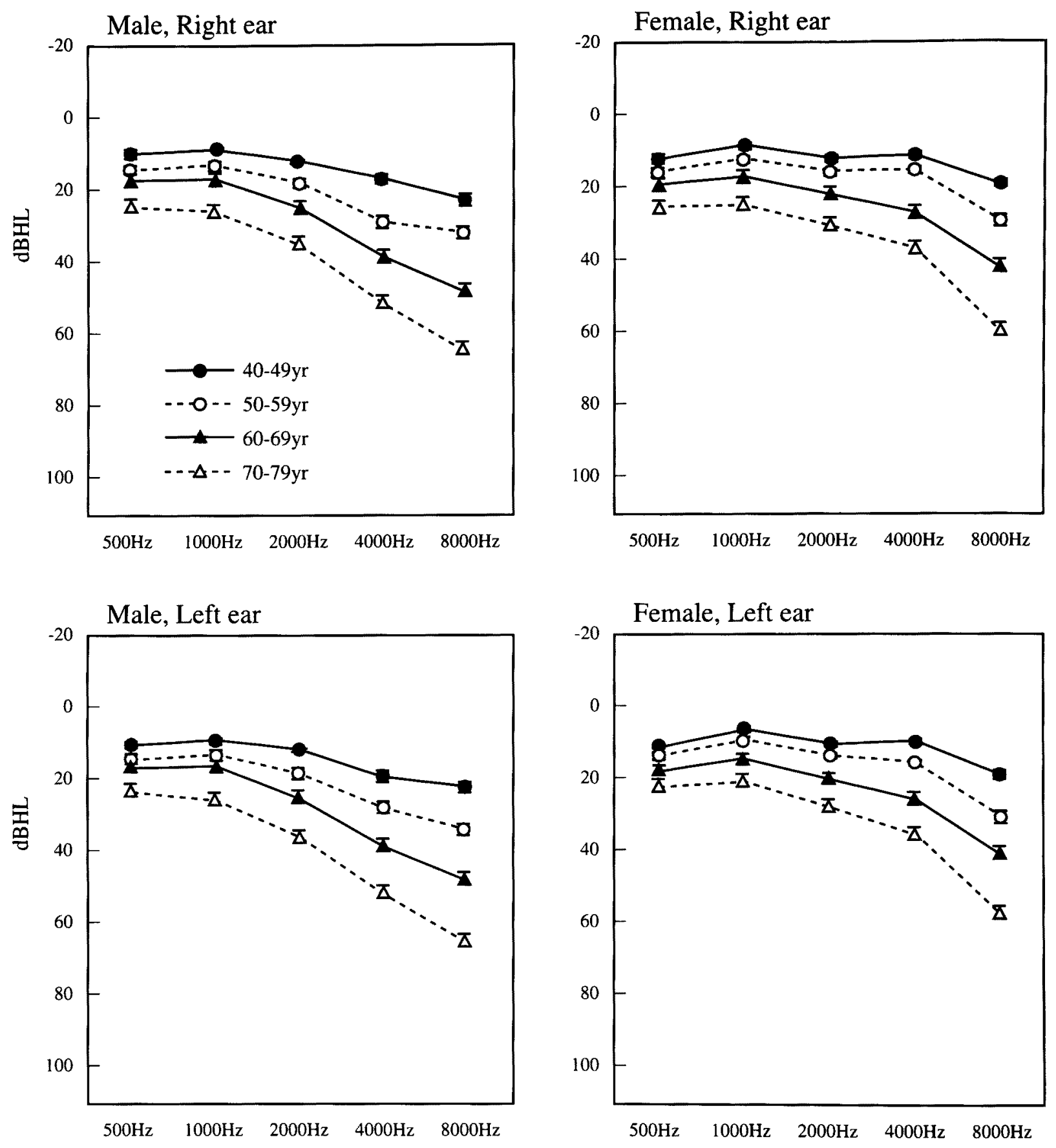

Figure 1. Air conduction pure tone thresholds by gender and ear. Error bar shows the standard error of the mean.

Age-related changes, gender differences and right/left ear differences in hearing thresholds were examined. There were statistically significant differences between almost any two age groups at each frequency in both genders, especially in higher frequencies. The trends of pure tone threshold by age group at each frequency for each gender were highly significant ( $p<$ $0.0001)$. A gender difference was clear at $4000 \mathrm{~Hz}$ in any age group $(\mathrm{p}<0.0001$ ). The differences were smaller but significant at $2000 \mathrm{~Hz}$ and $8000 \mathrm{~Hz}$. There were no significant gender differences at $500 \mathrm{~Hz}$ and $1000 \mathrm{~Hz}$ in any age group. As for lat- 
erality, almost no significant differences were observed at any frequencies in any age group in either males or females. Table 3 shows the 5,50 and 95 percentiles of air conduction pure tone thresholds at 500 to $8000 \mathrm{~Hz}$ by gender and age group.

The results of Spearman's correlation analysis between age and air conduction thresholds are listed in Table 4 . All of the correlation coefficients were highly significant $(p<0.0001)$. The higher frequencies were, the greater positive correlation coefficients were in both males and females.

\section{Self-perceived hearing difficulty}

Results from inquiry into hearing difficulties are shown in Figure 2 and Table 5. The percentages of subjects who were aware of hearing difficulty were $40.9 \%$ for males and $41.7 \%$ for females. There was no significant difference in the percentage of hearing difficulty between males and females $\left(\chi^{2}=0.05\right.$, $\mathrm{df}=1, \mathrm{NS})$. The number and percentage of subjects who were aware of hearing difficulty are shown in Table 5. The answers from 872 subjects with no apparent history of ear disease were analyzed. About $41 \%$ of these were aware of hearing difficulty in their daily life. Even in subjects aged in their 40 s, about one quarter were aware of hearing difficulty. There was a significant age difference in awareness the hearing difficulty $\left(\chi^{2}=37.1\right.$, $\mathrm{df}=3, \mathrm{p}<0.001$ ).

Mean pure tone thresholds for each age group are shown in the two panels according to the awareness of hearing difficulty (Figure 2). There were significant trends by age group at any frequency ( $p<0.0001$ ). The pure tone thresholds in subjects with hearing difficulty aged under 60 were compared with the thresholds in subjects without hearing difficulty aged 60 and over. The thresholds in the younger group with hearing difficulty were better than those in older subjects without hearing difficulty at any frequency $(\mathrm{p}<0.01)$.

\section{Tympanometric measurements}

Results from tympanometric measurements are shown in Table 6. No directional tendency related to aging was revealed on static admittance, on tympanometric peak pressure or on resonance frequency of the middle ear.

\section{DISCUSSION}

\section{Pure tone thresholds}

Roughly comparing the results of the present study with the Framingham Cohort Study, a representative international study, the average thresholds of $4000 \mathrm{~Hz}$ in males in their $60 \mathrm{~s}$ and $70 \mathrm{~s}$ and the average threshold of $8000 \mathrm{~Hz}$ in males in their $60 \mathrm{~s}$ were better in this study than in the Framingham Cohort Study ${ }^{8)}$. For females, the thresholds at any frequency were similar to those in the Framingham Cohort Study. In comparison with the Baltimore Longitudinal Study of Aging (BLSA) ${ }^{9}$, the results in the present study were worse to various extent than those in the BLSA at any frequency or in any generation, except at 8000 $\mathrm{Hz}$ in males in their $40 \mathrm{~s}$ and 50 s. Compared with previous domestic estimates, the findings shown through all age groups in this study resembled the longitudinal study reported by Ono ${ }^{10}$.

In reference to gender difference, it was indicated in many studies that the hearing acuity in men was poorer than in

Table 3. Percentiles of the air-conducted pure tone threshold by gender and age group.

\begin{tabular}{|c|c|c|c|c|c|c|c|c|c|c|c|c|c|c|c|c|}
\hline & \multirow[b]{2}{*}{ Age } & \multicolumn{3}{|c|}{$500 \mathrm{~Hz}$} & \multicolumn{3}{|c|}{$1000 \mathrm{~Hz}$} & \multicolumn{3}{|c|}{$2000 \mathrm{~Hz}$} & \multicolumn{3}{|c|}{$4000 \mathrm{~Hz}$} & \multicolumn{3}{|c|}{$8000 \mathrm{~Hz}$} \\
\hline & & $5 \%$ & $50 \%$ & $95 \%$ & $5 \%$ & $50 \%$ & $95 \%$ & $5 \%$ & $50 \%$ & $95 \%$ & $5 \%$ & $50 \%$ & $95 \%$ & $5 \%$ & $50 \%$ & $95 \%$ \\
\hline \multirow{4}{*}{ Male } & $40-49 \mathrm{yr}$ & 0.0 & 10.0 & 20.0 & 0.0 & 7.5 & 20.0 & 2.5 & 10.0 & 25.0 & 2.5 & 15.0 & 37.5 & 5.0 & 17.5 & 45.0 \\
\hline & $50-59 \mathrm{yr}$ & 2.5 & 12.5 & 30.0 & 2.5 & 10.0 & 37.5 & 5.0 & 15.0 & 40.0 & 7.5 & 22.5 & 55.0 & 10.0 & 30.0 & 60.0 \\
\hline & $60-69 \mathrm{yr}$ & 5.0 & 15.0 & 35.0 & 2.5 & 15.0 & 32.5 & 7.5 & 22.5 & 52.5 & 10.0 & 37.5 & 65.0 & 17.5 & 47.5 & 77.5 \\
\hline & $70-79 \mathrm{yr}$ & 7.5 & 20.0 & 50.0 & 5.0 & 22.5 & 57.5 & 12.5 & 32.5 & 67.5 & 17.5 & 52.5 & 80.0 & 32.5 & 67.5 & 90.0 \\
\hline \multirow{4}{*}{ Female } & $40-49 \mathrm{yr}$ & 2.5 & 10.0 & 22.5 & 0.0 & 5.0 & 17.5 & 2.5 & 10.0 & 25.0 & 0.0 & 7.5 & 22.5 & 2.5 & 17.5 & 45.0 \\
\hline & $50-59 \mathrm{yr}$ & 2.5 & 12.5 & 30.0 & 0.0 & 10.0 & 22.5 & 5.0 & 12.5 & 27.5 & 2.5 & 12.5 & 40.0 & 10.0 & 25.0 & 62.5 \\
\hline & $60-69 \mathrm{yr}$ & 7.5 & 15.0 & 37.5 & 2.5 & 12.5 & 35.0 & 5.0 & 17.5 & 40.0 & 5.0 & 22.5 & 52.5 & 15.0 & 38.8 & 72.5 \\
\hline & $70-79 \mathrm{yr}$ & 7.5 & 22.5 & 45.0 & 5.0 & 22.5 & 45.0 & 7.5 & 25.0 & 60.0 & 10.0 & 32.5 & 70.0 & 25.0 & 57.5 & 92.5 \\
\hline
\end{tabular}

Subjects with a history of ear diseases were excluded.

Table 4. Spearman's correlation coefficients between age and air conduction thresholds.

\begin{tabular}{|c|c|c|c|c|c|c|c|c|c|c|}
\hline & \multicolumn{2}{|c|}{$500 \mathrm{~Hz}$} & \multicolumn{2}{|c|}{$1000 \mathrm{~Hz}$} & \multicolumn{2}{|c|}{$2000 \mathrm{~Hz}$} & \multicolumn{2}{|c|}{$4000 \mathrm{~Hz}$} & \multicolumn{2}{|c|}{$8000 \mathrm{~Hz}$} \\
\hline & Right & Left & Right & Left & Right & Left & Right & Left & Right & Left \\
\hline & 0.46 & 0.39 & & & & & & & 06 & 0.69 \\
\hline & 0.41 & 0.41 & 0.51 & 0.48 & 0.50 & 0.51 & 0.57 & 0.61 & 0.67 & 0.66 \\
\hline
\end{tabular}

All correlation coefficients were significant $(p<0.0001)$. 

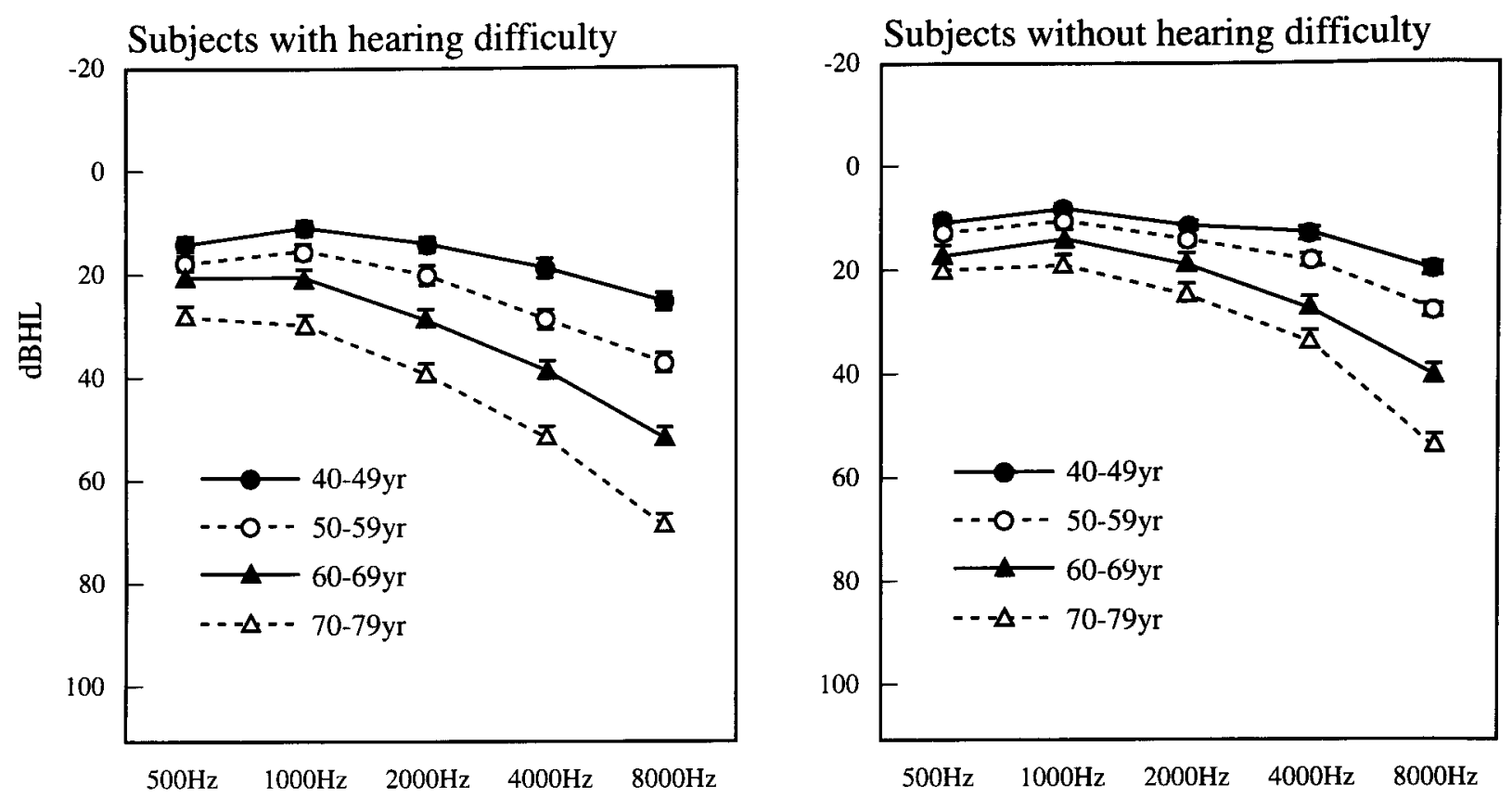

Figure 2. Air conduction pure tone thresholds according to awareness of hearing difficulty. Error bar shows the standard error of the mean. (Subjects with a history of ear diseases were excluded.)

Table 5. Number and percentage of subjects without history of ear disease who were aware of hearing difficulty by age group.

\begin{tabular}{crrrr}
\hline Age & \multicolumn{2}{c}{$\begin{array}{c}\text { Aware of hearing } \\
\text { difficulty }\end{array}$} & \multicolumn{2}{c}{$\begin{array}{c}\text { No hearing } \\
\text { difficulty }\end{array}$} \\
\hline $40-49 \mathrm{yr}$ & 61 & $(26.8 \%)$ & 166 & $(73.1 \%)$ \\
$50-59 \mathrm{yr}$ & 85 & $(39.2 \%)$ & 132 & $(60.8 \%)$ \\
$60-69 \mathrm{yr}$ & 95 & $(45.2 \%)$ & 115 & $(54.8 \%)$ \\
$70-79 \mathrm{yr}$ & 119 & $(54.6 \%)$ & 99 & $(45.4 \%)$ \\
\hline Total & 360 & $(41.3 \%)$ & 512 & $(58.7 \%)$ \\
\hline
\end{tabular}

Table 6. Percentiles of tympanometric measurements by gender and age group.

\begin{tabular}{|c|c|c|c|c|c|c|c|c|c|c|}
\hline & \multirow{2}{*}{ Age } & \multicolumn{3}{|c|}{$\begin{array}{c}\text { Tympanometric peak } \\
\text { pressure (daPa) }\end{array}$} & \multicolumn{3}{|c|}{ Static admittance (ml) } & \multicolumn{3}{|c|}{$\begin{array}{l}\text { Middle ear resonance } \\
\text { frequency }(\mathrm{Hz})\end{array}$} \\
\hline & & 5 th & 50 th & 95th & 5 th & 50 th & 95th & 5 th & 50th & 95th \\
\hline \multirow{5}{*}{ Male } & $40-49 \mathrm{yr}$ & -20.0 & 2.5 & 12.5 & 0.25 & 0.50 & 2.20 & 525 & 850 & 1100 \\
\hline & $50-59 y r$ & -47.5 & 2.5 & 15.0 & 0.25 & 0.55 & 2.75 & 475 & 850 & 1150 \\
\hline & $60-69 \mathrm{yr}$ & -87.5 & 2.5 & 12.5 & 0.20 & 0.40 & 1.85 & 550 & 888 & 1175 \\
\hline & $70-79 y r$ & -77.5 & 5.0 & 12.5 & 0.20 & 0.45 & 2.15 & 450 & 900 & 1200 \\
\hline & Total & -65.0 & 2.5 & 12.5 & 0.25 & 0.60 & 2.15 & 475 & 800 & 1100 \\
\hline \multirow{5}{*}{ Female } & $40-49 y \mathrm{r}$ & -50.0 & 2.5 & 12.5 & 0.30 & 0.60 & 1.65 & 550 & 775 & 1125 \\
\hline & $50-59 \mathrm{yr}$ & -57.5 & 2.5 & 15.0 & 0.25 & 0.60 & 1.55 & 475 & 800 & 1025 \\
\hline & $60-69 \mathrm{yr}$ & -92.5 & 2.5 & 10.0 & 0.25 & 0.65 & 1.50 & 500 & 800 & 1100 \\
\hline & $70-79 y r$ & -95.0 & 2.5 & 15.0 & 0.20 & 0.65 & 1.25 & 425 & 875 & 1100 \\
\hline & Total & -57.5 & 2.5 & 12.5 & 0.20 & 0.50 & 1.50 & 500 & 875 & 1175 \\
\hline
\end{tabular}


women, especially at higher frequencies ${ }^{8,9,11,12)}$. One of the probable reasons for the progress in male presbycusis was considered to be more risk of noise exposure for men than for women, such as military service, noisy jobs, daily use power tools (yard-keeping, home carpentry), or recreational noise (hunting, loud engines, loud music). Though these studies screened out their subjects from noise-induced hearing loss and otological diseases in various ways, it is impossible to rule out noise exposure and otological disease history from self-reports completely. The difference among hearing thresholds in each study may result partly from the degree of rigorous screening for causes of hearing loss besides aging. Recent domestic investigations found that the gender difference has been getting smaller than reported before ${ }^{13,14}$ ). Less difference in life-style between genders than before, due to the current reduced chance of military service, little daily power tool usage or hunting in Japan, could have contributed to this finding. In our study, a gender difference was still detected .

A right/left ear difference in hearing thresholds was not revealed in the present study, while laterality was observed in some other studies in which the hearing loss in the left ear was greater than that in the right ${ }^{8,15)}$.

\section{Self-perceived hearing difficulty}

There are several confounding factors which contribute to self-perception of hearing disability in the elderly. Though hearing threshold levels and word recognition influence selfperception, they are not as strong as determinants. The factors of central auditory processing disorder (CAPD), cognitive deficit or sociological status also affect the self-perception of a hearing handicap ${ }^{23,6)}$. While speech understanding deteriorates with worsening pure-tone sensitivity and CAPD, the demand for understanding speech decreases with aging, especially for noisy and degraded speech with which the difference in speech-understanding performance between elderly and young listeners with matched hearing sensitivity becomes obvious.

The inquiry used in the present analysis was not for certain listening situations imagined in detail, but for general situations. Therefore one subject might assume the optimal condition and another the worst. The explanation for the gap between hearing sensitivity and self-perceived difficulty in subjects aged 60 and over can be provided by considering their lower necessity to communicate under difficult listening situations.

\section{Tympanometric measurements}

Several investigations have shown the possibility of agerelated anatomical changes in the middle ear. Etholm and Belal found that all 34 temporal bones from individuals aged over 70 years showed moderate to severe arthritis in both the incudomalleal and incudostapedial joints ${ }^{16}$. Moreover, they reported only one of 32 cases, using audiometric studies, showed conductive hearing loss out of the 34 temporal bones. That means the arthritis in the ossicular joints can exist even though conductive hearing loss is not detected yet. Ruah et al. examined the tympanic membranes of 54 temporal bones from patients aged 33 weeks' gestation to 91 years microscopically ${ }^{17}$. They demonstrated that the tympanic membrane became less vascular, less cellular, more rigid, and less elastic with aging. They also discussed a finding that some older eardrums with no apparent history of otologic disease appeared thicker and less transparent, probably due to deposition of calcium molecules, which are known to have a particular predilection for agedegraded elastic fibers.

Tympanometric measurements are considered to reflect several aspects of middle ear mechanisms ${ }^{18}$. Tympanometric peak pressure at $226 \mathrm{~Hz}$ correlates highly with middle ear pressure. When tympanometry is performed with low frequency probe tones such as $226 \mathrm{~Hz}$, the middle ear system is mainly controlled by stiffness, because mass reactance is negligible. Therefore, static admittance is expected to change with changes in stiffness. Resonance occurs when the contributions of the mass and the stiffness components of the middle ear are equal. High resonance frequency is associated with middle ear conditions that produce abnormal stiffness in the middle ear, such as ossicular fixation or otosclerosis . Low resonance frequency is associated with eardrum abnormalities, ossicular discontinuity or mass lesions ${ }^{19,200}$. Regarding the anatomical changes with aging, the arthritis in ossicular joints or the higher rigidity of the tympanic membrane causes an increase in stiffness, while the greater thickness of the tympanic membrane with deposition of calcium molecules causes an increase in mass. These degeneration changes affect individuals to varying degrees. One probable reason why the present study did not show any systematic aging change in tympanometric measurements is that these inverse effects might cancel each other out.

There are only a few studies which have investigated the aging transition via tympanometry in the elderly population ${ }^{21,22)}$. Thompsen et al. reported no significant changes in static admittance or its components, susceptance, or conductance at 220 or $660 \mathrm{~Hz}$ in 20 to 79 year old subjects. Holte demonstrated no significant aging effect on the resonance frequency of the middle ear, static admittance at $226 \mathrm{~Hz}$ and tympanometric width at $226 \mathrm{~Hz}$ in 136 subjects in their $20 \mathrm{~s}$ to $90 \mathrm{~s}$. The present study also indicated no systematic aging change. However, the present findings provided useful information on the reference values for each generation.

\section{ACKNOWLEGMENTS}

This study was supported by a Grant-in-Aid for Research on Eye and Ear Sciences, Immunology, Allergy and Organ Transplantation form the Ministry of Health and Welfare of Japan. 


\section{REFERENCES}

1. Schuknecht H.F. : Pathology of the Ear Lea\&Febiger, Malvern, PA 1993; 415-446.

2. Working Group on Speech Understanding and Aging Speech understanding and aging. J Acoust Soc Am, 1988;83(3):859-893.

3. Jerger J, Oliver T, Pirozzolo F. Impact of central auditory processing disorder and cognitive deficit on the selfassessment of hearing handicap in the elderly. J Am Acad Audiol 1990;1:75-80.

4. Gordon-Salant S. Effects of aging on response criteria in speech-recognition tasks. J Speech Hear Res 1986;29:155-162.

5. Gordon-Salant S, Lantz J, Fitzgibbons P. Age effects on measures of hearing disability. Ear Hear 1994;15(3):262265.

6. Gatehouse S. Determinations of self-reported disability in older subjects. Ear Hear 1990;11(5) Suppl: 57S-65S.

7. SAS Procedures Guide, Release 6.12 Edition. SAS Institute Inc., Cary, NC, 1997.

8. Gates G, Cooper J, Kannel W, Miller N. Hearing in the elderly: The Framingham Cohort,1983-1985. Ear Hear 1990;11:247-256.

9. Pearson JD, Morrell CH, Gordon-Salant S, et al. Gender differences in a longitudinal study of age-associated hearing loss. J Acoust Soc Am 1995;97(2):1196-1205.

10. Ono Y. A longitudinal study of hearing level aggravation due to aging. Journal of the Oto-Rhino-Laryngological Society of Japan 1996;99:558-566 (In Japanese with English abstract).

11. Kryter K. Presbycusis, sociocusis and nosocusis. J Acoust Soc Am 1983;73(6):1897-1917.
12. Wilson DH, Walsh PG, Sanchez $L$ et al. The epidemiology of hearing impairment in an Australian adult population. Int J Ep 1999;28:247-252.

13. Yagi M, Kawabata I, Sato $T$ et al. Hearing acuity in the elderly in Japan. Journal of the Oto-RhinoLaryngological Society of Japan. 1996;99: 869-874 (In Japanese with English abstract).

14. Yanagita $\mathbf{N}$, Nakashima $T$, Kusakari $\mathbf{J}$ et al. Pure tone hearing level in people 75 years or more. Audiology Japan 1996;39:722-727 (In Japanese with English abstract).

15. Rudin R, Rosenhall $U$, Svardsudd $K$. Hearing capacity in samples of men from the general population. The study of men born in 1913 and 1923. Scandinavian Audiology 1988;17:3-10.

16. Etholm,B, Belal,A. Senile changes in the middle ear joints. Ann Otolaryngol 1974;83:49-54.

17. Ruah,CB, Schachern,PA, Zelterman,D et al. Age-related morphologic changes in the human tympanic membrane. Arch Otolaryngol Head Neck Surg. 1991;117: 627-634.

18. Shanks J , Lilly D , Margolis R et al. Tympanometry. J Speech Hear Dis 1988;53:354-377.

19. Margolis R, Goycoolea H. Multifrequency tympanometry in normal adults. Ear Hear 1993;14(6):408-413.

20. Shahnaz N, Polka L. Standard and multifrequency tympanometry in normal and otosclerotic ears. Ear Hear 1997;18(4):326-341.

21. Thompsen DJ, Sills JA, Racke KR, Bui DM. Acoustic admittance and the aging ear. $J$ Speech Hear Res 1979;22:29-36.

22. Holte L. Aging Effects in Multifrequency Tympanometry. Ear Hear 1996;17(1):12-18. 